\title{
ADSORÇÃO DE ÁCIDOS GRAXOS LIVRES PRESENTES EM BIOCOMBUSTÍVEIS EMPREGANDO LAMA VERMELHA ATIVADA TERMICAMENTE COMO ADSORVENTE
}

\author{
A. A. MANCIO ${ }^{1}$, K. M. B. COSTA $^{2}$, I. V. CURCINO ${ }^{3}$, F. L. C. TEIXEIRA ${ }^{4}$, S. A. P. MOTA ${ }^{5}$, N. T. \\ MACHADO $^{6}$ \\ ${ }^{1}$ Universidade Federal do Pará, Discente do Programa de Pós-Graduação em Engenharia de \\ Recursos Naturais da Amazônia (PRODERNA) \\ ${ }^{2}$ Universidade Federal do Pará, Discente do Programa de Pós-Graduação em Engenharia \\ Química (PPGEQ) \\ ${ }^{3}$ Universidade Federal do Pará, Discente da Faculdade de Engenharia Química \\ ${ }^{4}$ Instituo Federal do Pará, Discente do Instituo Federal do Pará \\ ${ }^{5}$ Universidade Federal do Pará, Colaborador do Programa de Pós-Graduação em Engenharia \\ Química (PPGEQ) \\ ${ }^{6}$ Universidade Federal do Pará, Docente da Faculdade de Engenharia Química \\ e-mail para contato: dedeiamm@yahoo.com.br
}

\begin{abstract}
RESUMO - O presente trabalho investigou o uso de lama vermelha ativada termicamente $\left(400\right.$ e $\left.600^{\circ} \mathrm{C}\right)$ como adsorvente para a remoção de ácidos graxos livres (ácidos carboxílicos) a partir de frações destiladas proveniente do Produto Líquido Orgânico (PLO) obtido por craqueamento termocatalítico de óleo vegetal. A capacidade da lama vermelha como adsorvente em relação à adsorção dos ácidos graxos livres foi avaliada através de estudos cinéticos em sistema de batelada, a qual foi determinada pela variação na concentração de ácidos graxos livres no biocombustível antes e depois da adsorção. Os resultados mostraram que a lama vermelha ativada termicamente a 400 e $600^{\circ} \mathrm{C}$ são capazes de remover os ácidos de frações destiladas com diferentes teores de ácidos graxos livres (AGL). Porém, a lama vermelha ativada a $400^{\circ} \mathrm{C}$ mostra ser levemente mais eficiente que a lama vermelha a $600^{\circ} \mathrm{C}$. Os melhores resultados foram para lama vermelha ativada a $400^{\circ} \mathrm{C}$ e alimentações A, B, C D e E, em que permaneceram $0,0 \%, 70,8938 \%$, 63,6004\%, 81,6655\% e 94,9957\% de AGLs residuais, respectivamente e para lama vermelha ativada a $600^{\circ} \mathrm{C}$ e alimentações $\mathrm{A}$, D e E em que permaneceram 74,7430\%, 74,7430\% e 95,0879\% de AGLs residuais, respectivamente.
\end{abstract}

\section{INTRODUÇÃO}

O processo de craqueamento de óleos vegetais ou gorduras animais ocorrem em dois estágios sucessivos e distintos. O primeiro estágio, conhecido como craqueamento primário, é caracterizado pela formação de espécies ácidas através da decomposição das moléculas de triglicerídeos que ocorrem através da quebra de ligações C-O dentro da parte glicerídica da 


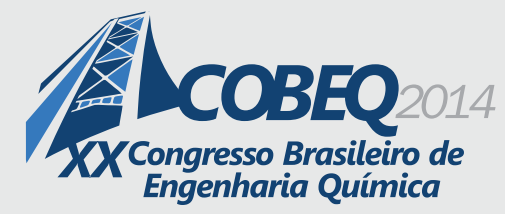

cadeia do triglicerídeo. O segundo estágio é caracterizado pela degradação de ácidos produzidos no primeiro estágio levando a formação de hidrocarbonetos com propriedades similares aqueles produtos do petróleo. Este estágio é chamado de craqueamento secundário (PRADO e ANTONIOSI FILHO, 2009). A acidez de um biocombustível obtido por craqueamento é a soma da acidez de seus compostos e, os ácidos carboxílicos, geralmente, ácidos graxos livres, são os grupos de compostos mais ácidos presente nos mesmos (OASMAA; ELLIOTT; KORHONEN, 2010).

Os produtos obtidos por craqueamento térmico-catalítico apresentam menores quantidades de compostos ácidos. Portanto, o catalisador apresenta atividade no processo de craqueamento secundário, em que os ácidos graxos decompõem-se para formar hidrocarbonetos (PRADO e ANTONIOSI FILHO 2009). Porém, apesar de o craqueamento térmico-catalítico produzir biocombustíveis com menores níveis de acidez, o que se tem observado na literatura é que mesmo na presença de catalisadores, o craqueamento térmico-catalítico não reduz a acidez para valores satisfatórios como pode ser visualizado na Tabela 1.

Tabela 1 - Índice de acidez de biocombustíveis brutos e suas frações destiladas, obtidos por craqueamento térmico-catalítico com diferentes quantidades de bauxita calcinada

\begin{tabular}{ccccc}
\hline Quantidade de & \multicolumn{3}{c}{ Índice de acidez (mg KOH/g) } \\
\cline { 2 - 2 } catalisador & Biocombustível bruto & Fração pesada & Fração leve \\
\hline Sem catalisador & 120,9 & 96,8 & 63,7 \\
10\% de bauxita & 44,6 & 60,2 & 43,0 \\
20\% de bauxita & 35,0 & 20,7 & 36,6 \\
30\% de bauxita & 27,1 & 17,5 & 33,4 \\
\hline
\end{tabular}

A maioria das formas propostas para resolver ou minimizar o problema da elevada acidez dos biocombustíveis ainda esta baseada em intervenções empíricas focadas sobre situações particulares. As soluções propostas incluem o uso de blends de óleos, substituição do material do equipamento (atualmente, a forma mais usada e menos onerosa para reduzir a corrosão), injeção local de inibidores e a remoção de ácidos naftênicos por extração ou adsorção. A adsorção é uma potencial solução de baixo custo e também tem mostrado capacidade de remover os ácidos naftênicos presentes em combustíveis derivado do petróleo. Zeolitas, alumino-silicatos a partir do resíduo proveniente do processo de fabricação de catalisadores, sílica gel, argilas, alumina, mistura de óxidos de magnésio e alumínio, e resinas de troca iônica foram propostos como adsorventes para ácidos naftênicos, uma vez que esses ácidos podem ser recuperados usando solventes polares como cetonas e alcoóis (SILVA et al., 2013).

Existem alguns materiais com grande potencial de adsorção, entre estes se encontra a lama vermelha, um resíduo gerado em grande escala no processo de fabricação de alumínio. Este resíduo, quando adequadamente tratado (térmica ou quimicamente) apresenta propriedades de adsorção promissoras (WANG et al., 2008), podendo viabilizar sua aplicação na remoção de ácidos graxos livres presentes em biocombustíveis. Assim, a ideia é que as propriedades dos biocombustíveis melhorados por adsorção, isto é, sem a presença de ácidos, estariam muito mais perto da alimentação de hidrocarbonetos típicos do que o biocombustível original, e assim, o 


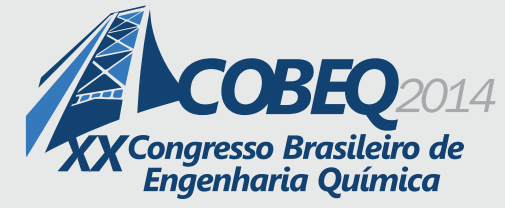

19 a 22 de outubro de 2014

Florianópolis/SC

mesmo protocolo analítico aplicado para as alimentações das refinarias de petróleo poderiam ser usadas. (OASMAA; ELLIOTT; KORHONEN, 2010).

Neste contexto, o presente trabalho tem como objetivo principal avaliar o efeito da concentração inicial de ácidos graxos livres, isto é, da alimentação (frações destiladas proveniente do produto líquido orgânico produzido por craqueamento térmico-catalítico do óleo de palma) sobre a adsorção dos ácidos graxos livres, bem como avaliar a capacidade da lama vermelha ativada termicamente a $400^{\circ} \mathrm{C}$ e $600^{\circ} \mathrm{C}$ como adsorventes em relação à adsorção dos ácidos graxos livres.

\section{MATERIAL E MÉTODOS}

\subsection{Adsorventes}

O adsorvente empregado no presente trabalho foi lama vermelha in natura, a qual foi cedida pela empresa ALUNORTE S/A. Para a lama vermelha ser utilizada como adsorvente, realizou-se algumas etapas de pré-tratamento conforme descritas a seguir: (1) Secagem da lama vermelha in natura: a secagem da lama vermelha foi realizada em estufa de recirculação de por 24 h a $110^{\circ} \mathrm{C}$; (2) Desagregação da lama vermelha seca: após a secagem, aproximadamente $2 \mathrm{~kg}$ de lama vermelha seca foi submetida a uma etapa de desagregação em um moinho de bolas por um período de 30 minutos; (3) Ativação térmica: após a lama vermelha ter passado por uma etapa de secagem e desagregação, duas porções de $750 \mathrm{~g}$ de lama vermelha seca e desagregada foi submetida a ativação térmica, cada uma porção a temperaturas diferentes, 400 e $600^{\circ} \mathrm{C}$, com o objetivo de avaliar o efeito da temperatura de ativação sobre a adsorção de ácidos graxos livres. A ativação térmica da lama vermelha foi realizada em um forno elétrico por um período de $4 \mathrm{~h}$ e taxa de aquecimento de $5^{\circ} \mathrm{C} / \mathrm{min}$.

\subsection{Fração destilada}

Tabela 2 - Número de ácidos totais das frações destiladas na faixa de temperatura de $235-305^{\circ} \mathrm{C}$ destinadas a desacidificação por adsorção

\begin{tabular}{cc}
\hline Alimentação & NAT (mg KOH/g) \\
\hline A & 1,5853 \\
B & 11,9923 \\
C & 20,7590 \\
D & 33,6736 \\
E & 84,3982 \\
\hline
\end{tabular}

As frações destiladas usadas neste trabalho adotadas como alimentação foram obtidas no Laboratório de Processos de Separações Térmicas (THERMTEK/FEQ/ITEC/UFPA) através da destilação a pressão atmosférica (coluna de destilação piloto) do Produto Líquido Orgânico produzido por craqueamento termocatalítico do óleo de palma. Para o desenvolvimento do presente estudo selecionou cinco frações destiladas na faixa de temperatura de $235-305^{\circ} \mathrm{C}$, as quais cada uma das frações apresentava um teor de ácido graxo livre diferente, conforme 


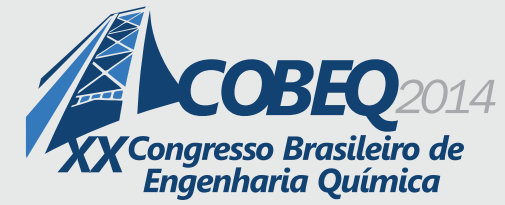

Engenharia Química
19 a 22 de outubro de 2014

Florianópolis/SC

apresentado na Tabela 2, com o objetivo de avaliar o efeito do teor de ácido graxo livre inicial (da alimentação) sobre a adsorção dos mesmos.

\subsection{Cinética de adsorção dos ácidos graxos livres}

Os experimentos de cinética de adsorção dos ácidos graxos livres foram realizados no sistema de batelada em frascos Erlenmeyer de $250 \mathrm{~mL}$, os quais foram dispostos em uma mesa agitadora (AGIF/RES-MCT-010/Ética/Q-842-210) com agitação orbital para que as frações destiladas tivessem o contato adequado com o adsorvente. Cinco gramas de fração destilada e 5\% de adsorvente (lama vermelha ativada termicamente) foram adicionados em cada Erlenmeyer e, em seguida, agitou-se por tempos pré-estabelecidos.

As condições experimentais mantidas constantes foram temperatura ambiente, pressão atmosférica, velocidade de agitação de $160 \mathrm{rpm}$, porcentagem de adsorvente (5\%), variando apenas o teor de ácidos graxos livres iniciais (número de ácidos totais da alimentação) e o tempo de contato $(0 ; 2,5 ; 5 ; 10 ; 20 ; 30 ; 40 ; 50 ;$ e 60$)$ a fim de se obter cinéticas de adsorção. Após o procedimento de adsorção, o conteúdo do frasco foi submetido à filtração a vácuo, empregando papel filtro Whatman $\mathrm{n}^{0} 1$, obtendo-se como parte filtrada uma fração destilada desacidificada, a qual foi determinada o número de ácidos totais de acordo com o método padrão da ASTM D 974.

O procedimento experimental para a obtenção das cinéticas de adsorção descrito acima foi realizado com lama vermelha ativada a $400^{\circ} \mathrm{C}$ (LV400) aplicada as alimentações A, B, C, D e E, enquanto a lama vermelha ativada a $600^{\circ} \mathrm{C}$ (LV600) foi aplicada as alimentações A, D e E.

A avaliação da quantidade relativa de ácidos graxos livres removidos foi realizada através e titulação colorimétrica, em que foi utilizado o método padrão da ASTM D 974 para determinar o número de ácidos totais (NAT) antes e depois da adsorção.

\section{RESULTADOS E DISCUSSÃO}

Duas séries de experimentos foram realizadas para avaliarmos o efeito da quantidade inicial de ácidos graxos livres na alimentação e a ativação térmica da lama vermelha sobre a adsorção de ácidos graxos livres. Os resultados experimentais são apresentados nas Tabelas 2 e 3 e na forma de gráficos de quantidade relativa de AGLs adsorvidos por grama de adsorvente contra o tempo de adsorção conforme apresentado nas Figuras 1-5.

De acordo com as Tabelas 2 e 3 e com a Figura 1, verificou-se que a lama vermelha ativada a $400^{\circ} \mathrm{C}$ foi mais eficiente do que a lama vermelha ativada a $600^{\circ} \mathrm{C}$ em relação à adsorção de ácidos graxos livres da alimentação A, enquanto para a alimentação D e E a eficiência e o comportamento dos dois adsorventes são muito similares, embora os pontos da cinética para a alimentação $\mathrm{D}$ com lama vermelha ativada a $600^{\circ} \mathrm{C}$ tenha destoado nos primeiros 20 minutos. A diferença em relação à eficiência da lama vermelha ativada a $400^{\circ} \mathrm{C}$ e a $600^{\circ} \mathrm{C}$ pode ser atribuída as suas estruturas e texturas, conforme discutido por Wang et al. (2008). 
Tabela 3 - Quantidade relativa de ácidos graxos livres residuais em função do tempo de contato da alimentação com o adsorvente (lama vermelha ativada termicamente a $400^{\circ} \mathrm{C}$ )

\begin{tabular}{cccccc}
\hline Tempo de & \multicolumn{5}{c}{ Ácidos Graxos Livres Residuais (\%) } \\
\cline { 2 - 6 } contato (min) & $\mathrm{A}$ & $\mathrm{B}$ & $\mathrm{C}$ & $\mathrm{D}$ & $\mathrm{E}$ \\
\hline 0 & 100,00 & 100,0000 & 100,0000 & 100,0000 & 100,0000 \\
2,5 & 47,0321 & 84,0998 & 97,1670 & 86,0065 & 95,7092 \\
5 & 0,0000 & 89,5608 & 63,6004 & 82,0073 & 97,0715 \\
10 & 0,0000 & 94,0378 & 88,2947 & 82,3880 & 95,8518 \\
20 & 0,0000 & 89,5608 & 91,9592 & 81,6655 & 96,5439 \\
30 & 0,0000 & 81,3197 & 100,7004 & 83,3579 & 96,6101 \\
40 & 0,0000 & 70,8938 & 97,0315 & 85,0960 & 94,9957 \\
50 & 0,0000 & 85,4899 & 94,0315 & 86,0086 & 98,6427 \\
60 & 66,0947 & 91,7447 & 92,7506 & 82,4255 & 96,2344 \\
\hline
\end{tabular}

Alimentações: A = 1,5853 mg KOH/g; B = 11,9923 mg KOH/g; C = 20,7590 mg KOH/g; D = 33,6736 mg KOH/g; $\mathrm{E}=84,3982 \mathrm{mg} \mathrm{KOH} / \mathrm{g}$.

Tabela 4 - Quantidade relativa de ácidos graxos livres residuais em função do tempo de contato da alimentação com o adsorvente (lama vermelha ativada termicamente a $600^{\circ} \mathrm{C}$ )

\begin{tabular}{cccc}
\hline \multirow{2}{*}{ Tempo de contato (min) } & \multicolumn{3}{c}{ Ácidos Graxos Livres Residuais (\%) } \\
\cline { 2 - 4 } & $\mathrm{A}$ & $\mathrm{D}$ & $\mathrm{E}$ \\
\hline 0 & 100,0000 & 100,0000 & 100,0000 \\
2,5 & 80,2561 & 80,2561 & 96,8586 \\
5 & 83,4669 & 83,4669 & 97,4508 \\
10 & 81,9025 & 81,9025 & 95,9159 \\
20 & 90,1848 & 90,1848 & 96,2422 \\
30 & 86,7533 & 86,7533 & 96,9612 \\
50 & 74,7430 & 74,7430 & 95,2916 \\
60 & 81,9277 & 81,9277 & 95,9661 \\
& 78,7990 & 78,7990 & 95,0879 \\
\hline
\end{tabular}

Alimentações: A = 1,5853 mg KOH/g; B = 11,9923 mg KOH/g; C = 20,7590 mg KOH/g; D = 33,6736 mg KOH/g; $\mathrm{E}=84,3982 \mathrm{mg} \mathrm{KOH} / \mathrm{g}$.

A partir dos resultados obtidos, observa-se através das Figuras 1-5 que a quantidade relativa de AGLs adsorvidos aumenta como tempo, alcança uma quantidade mínima nas cinéticas de adsorção das alimentações B, C, D e E (Figuras 2, 3, 4 e 5). Porém, observou-se que as curvas plotadas para cinética de adsorção das referidas alimentações não foram uniformes, indicando que o equilíbrio de adsorção não foi alcançado. Portanto, só foi possível observar o tempo de contato necessário para alcançar o equilíbrio de adsorção dos AGLs presente na alimentação A, o qual foi de 10 min tanto com lama vermelha ativada a $400^{\circ} \mathrm{C}$ como com lama vermelha ativada a $600^{\circ} \mathrm{C}$.

Apesar da não uniformidade das curvas de cinética de adsorção, os resultados mostram que tanto a lama vermelha ativada a $400^{\circ} \mathrm{C}$ como a $600^{\circ} \mathrm{C}$ conseguem remover, com desempenho distinto, ácidos graxos livres presentes nas cinco frações destiladas com diferentes teores de 
ácidos. Silva et al., (2013) também conseguiram remover ácidos carboxílicos, porém, de frações destiladas modelos do petróleo, empregando argila comercial como adsorvente.

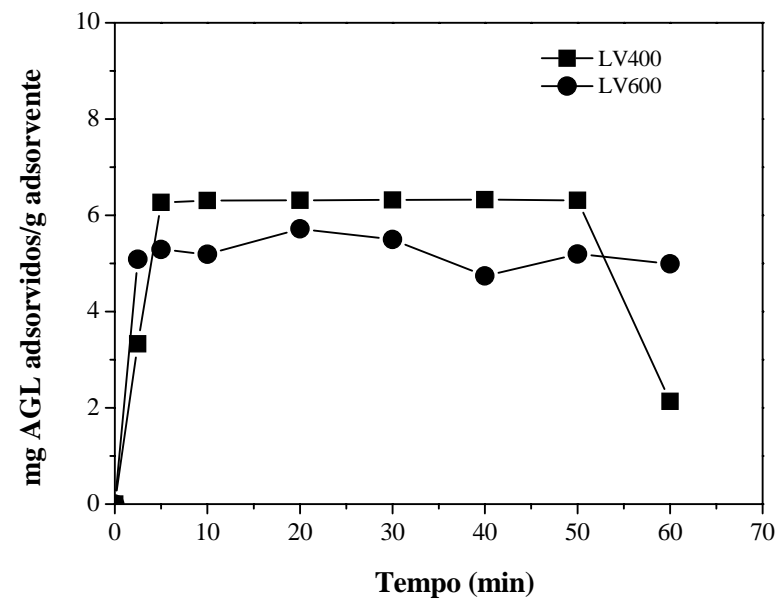

$$
\#
$$

Figura 1 - Cinética de adsorção de ácidos graxos livres da alimentação A (NAT = 1,5853 $\mathrm{mg} \mathrm{KOH} / \mathrm{g}$ ) com $5 \%$ de lama vermelha ativada a 400 e $600^{\circ} \mathrm{C}$.

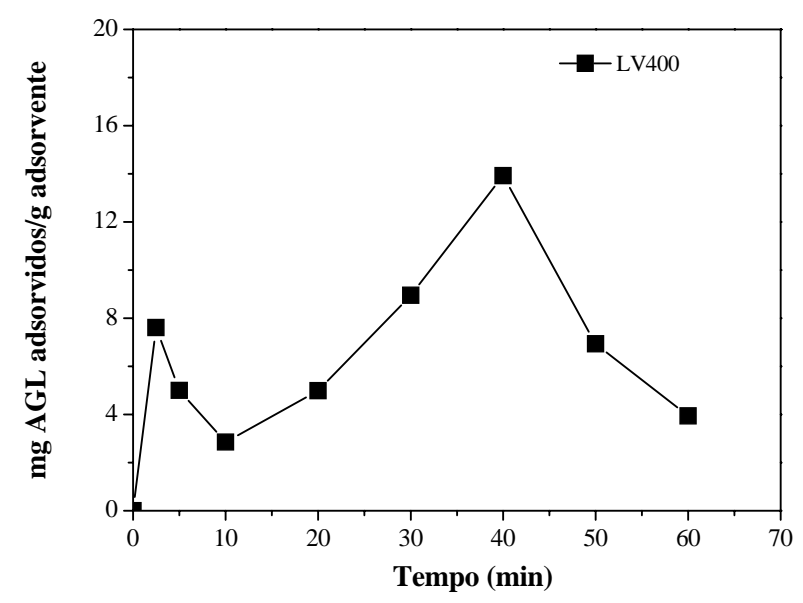

Figura 2 - Cinética de adsorção de ácidos graxos livres da alimentação B (NAT = 11,9923 $\mathrm{mg} \mathrm{KOH} / \mathrm{g}) \mathrm{com} 5 \%$ de lama vermelha ativada a $400^{\circ} \mathrm{C}$.

Sabendo que a alimentação de frações destiladas em uma unidade de desacidificação por adsorção pode ter diferentes teores de ácidos graxos livres, entender o efeito da concentração inicial de AGLs nas frações destiladas sobre a adsorção de AGLs é importante em um processo comercial. Os resultados deste trabalho mostram que não foi possível afirmar que quanto maior a concentração inicial do soluto, maior é a taxa inicial de adsorção como já foi observado em outros estudos, pois verificou-se com as curvas de algumas cinéticas que o incremento no teor de ácidos graxos livres favorece uma redução na taxa inicial de adsorção, enquanto que em outras o incremento no teor de AGLs favorece um aumento sobre a taxa inicial de adsorção como foi constatado por Silva (2010). 
Além disso, tem-se que apesar da taxa inicial de adsorção aumentar, em algumas situações, com o aumento do teor de ácidos graxos livres presentes nas frações destiladas (Figura 1), quanto maior o teor de ácidos da alimentação menor é o efeito de adsorção por parte da lama vermelha ativada em relação à quantidade inicial de ácidos (Tabela 2 e 3).

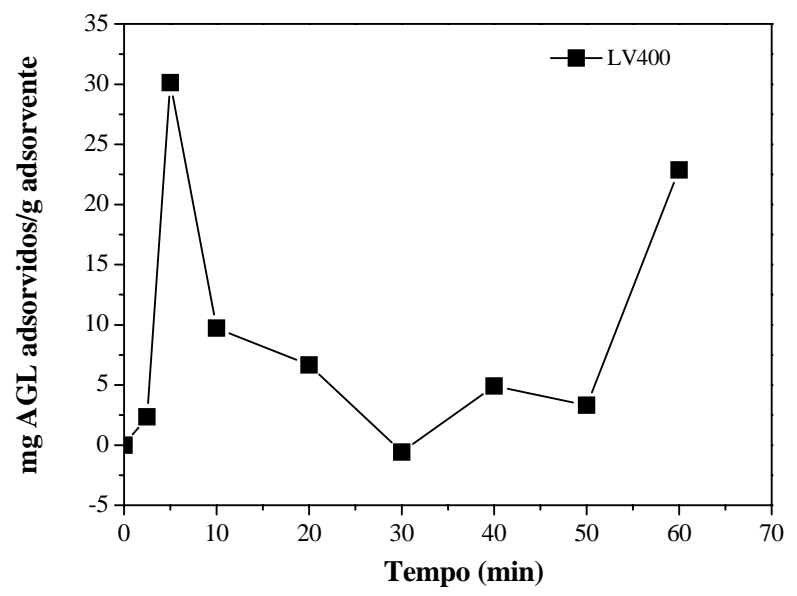

Figura 3 - Cinética de adsorção de ácidos graxos livres da alimentação C (NAT = 20,7590 $\mathrm{mg} \mathrm{KOH} / \mathrm{g}$ ) com lama vermelha ativada a $400^{\circ} \mathrm{C}$.

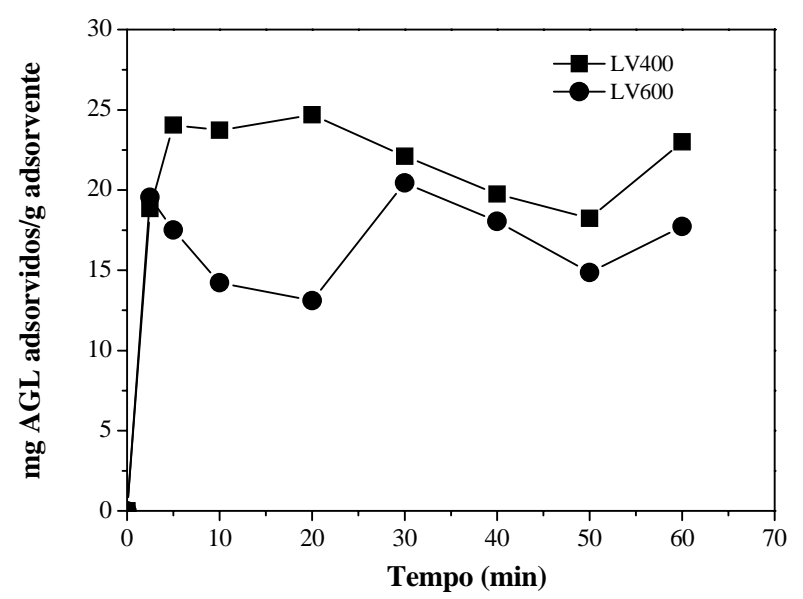

Figura 4 - Cinética de adsorção de ácidos graxos livres da alimentação D (NAT = 33,6736 $\mathrm{mg} \mathrm{KOH} / \mathrm{g}$ ) com $5 \%$ de lama vermelha ativada a 400 e $600^{\circ} \mathrm{C}$. 


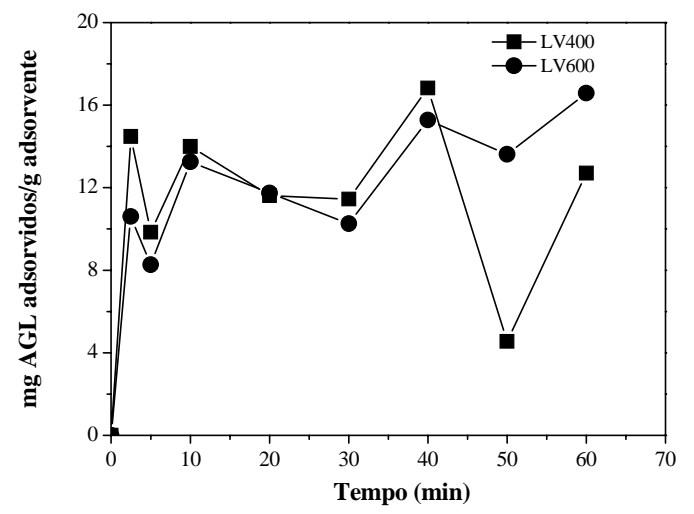

Figura 5 - Cinética de adsorção de ácidos graxos livres da alimentação E (NAT = 84,3982 $\mathrm{mg} \mathrm{KOH} / \mathrm{g}$ ) com $5 \%$ de lama vermelha ativada a 400 e $600^{\circ} \mathrm{C}$.

\section{CONCLUSÃO}

De acordo com os resultados apresentados acima, foi possível determinar o tempo necessário para alcançar o equilíbrio de adsorção de AGLs apenas para a alimentação A, o qual foi de 10 min e, a lama vermelha ativada a duas temperaturas diferentes, 400 e $600^{\circ} \mathrm{C}$, mostrou-se capaz de remover os ácidos graxos livres (AGL) de frações destiladas, com diferentes teores de ácidos, provenientes do produto líquido orgânico. Além disso, não se verificou uma relação direta entre teor de AGLs e seu efeito sobre a adsorção dos mesmos. Porém, verificou-se que quanto maior o teor de AGL menor é o efeito da remoção de ácidos quando comparada a quantidade de ácidos presentes na alimentação e que a lama vermelha ativada a $400^{\circ} \mathrm{C}$ mostra ser levemente mais eficiente que a lama vermelha a $600^{\circ} \mathrm{C}$, onde os melhores resultados foram: para lama vermelha ativada a $400^{\circ} \mathrm{C}$ e alimentações $\mathrm{A}, \mathrm{B}, \mathrm{C} \mathrm{D}$ e $\mathrm{E}$, em que permaneceram $0.0,70.8938$, $63.6004,81.6655$ e 94,9957\% de AGLs residuais, respectivamente; e para lama vermelha ativada a $600^{\circ} \mathrm{C}$ e alimentações A, D e E em que permaneceram 74.7430, 74.7430 e 95,0879\% de AGLs residuais, respectivamente.

\section{REFERÊNCIAS}

OASMAA, A.; ELLIOTT, D. C.; KORHONEN, J. Acidity of Biomass Fast Pyrolysis Bio-oils. Energy Fuels. V. 24, pag. 6548-6554, 2010.

PRADO, C.M.R.; ANTONIOSI FILHO N. R. Production and characterization of the biofuels obtained by thermal cracking and thermal catalytic cracking of vegetable oils. J. Anal. Appl. Pyrolysis. V. 86, pag. 338-347, 2009.

SILVA, J. P.; COSTA, A. L. H.; CHIARO, S. S. X.; DELGADO, B. E. P. C.; FIGUEIREDO, M. A. G.; SENNA, L. F. Carboxylic acid removal from model petroleum fractions by a commercial clay adsorbent. Fuel Processing Technology. V. 112, pag. 57-63, 2013.

WANG, S.; ANG, H.M.; TADÉ, M.O. Novel applications of red mud as coagulant, adsorbent and catalyst for environmentally benign processes. Chemosphere. V. 72, p. 1621-1635, 2008. 